\title{
Complex epigenetic regulation of Engrailed-2 (EN-2) homeobox gene in the autism cerebellum
}

\author{
SJ James ${ }^{1}$, Svitlana Shpyleva ${ }^{1}$, Stepan Melnyk ${ }^{1}$, Oleksandra Pavliv ${ }^{1}$ and IP Pogribny ${ }^{2}$
}

The elucidation of epigenetic alterations in the autism brain has potential to provide new insights into the molecular mechanisms underlying abnormal gene expression in this disorder. Given strong evidence that engrailed-2 (EN-2) is a developmentally expressed gene relevant to cerebellar abnormalities and autism, the epigenetic evaluation of this candidate gene was undertaken in 26 case and control post-mortem cerebellar samples. Assessments included global DNA methylation, EN-2 promoter methylation, $E N-2$ gene expression and $E N-2$ protein levels. Chromatin immunoprecipitation was used to evaluate trimethylation status of histone H3 lysine 27 (H3K27) associated with gene downregulation and histone H3 lysine 4 (H3K4) associated with gene activation. The results revealed an unusual pattern of global and EN-2 promoter region DNA hypermethylation accompanied by significant increases in EN-2 gene expression and protein levels. Consistent with EN-2 overexpression, histone H3K27 trimethylation mark in the EN-2 promoter was significantly decreased in the autism samples relative to matched controls. Supporting a link between reduced histone H3K27 trimethylation and increased EN-2 gene expression, the mean level of histone H3K4 trimethylation was elevated in the autism cerebellar samples. Together, these results suggest that the normal EN-2 downregulation that signals Purkinje cell maturation during late prenatal and early-postnatal development may not have occurred in some individuals with autism and that the postnatal persistence of $E N-2$ overexpression may contribute to autism cerebellar abnormalities.

Translational Psychiatry (2013) 3, e232; doi:10.1038/tp.2013.8; published online 19 February 2013

\section{Introduction}

Engrailed-2 ( $E N-2)$ is considered to be an autism susceptibility gene based on neuroanatomical parallels between autism and cerebellar developmental abnormalities in rodent models, and also on family linkage studies indicating an overtransmission of $E N-2$ polymorphic variants from parents to affected children. ${ }^{1}$ In mice, EN-2 is highly expressed in Purkinje cells during fetal and early-postnatal development acting primarily as a transcriptional repressor until it is downregulated during the perinatal period. ${ }^{2} E N-2$ is also expressed in hindbrain nuclei involved in the development of serotonin (raphe nucleus) and norepinephrine (locus coeruleus) neurotransmitter systems that have been implicated in autism. ${ }^{3}$ Importantly, normal timing of Purkinje cell maturation and cerebellar patterning is critically dependent on perinatal $E N-2$ downregulation, ${ }^{2}$ which is disrupted with $E N-2$ overexpression. ${ }^{4}$ Although human studies are limited, expression analysis of 18- to -21-week-old fetuses indicated widespread $E N-2$ gene expression throughout the mid-/hindbrain regions including the cerebellar cortex and deep nuclei at 40-week gestation. ${ }^{5,6}$ The human EN-2 gene is composed of two exons separated by a single intron and spans only $8 \mathrm{~kb}$ of DNA mapping to $7 q 36.3$, just distal to a region that has been reproducibly associated with autism in linkage studies. ${ }^{7,8}$

Anomalies in the cerebellum are arguably the most reproducible neuroanatomical alterations in the autism brain. Most frequently reported is a reduction in Purkinje cell number that appears to occur in the late prenatal period coinciding with the downregulation of $E N-2$, although other studies suggest this may not occur in all patients with autism. ${ }^{2,9-13}$ Imaging studies have reported vermis hypoplasia and reduction in cerebellar volume in some patients with autism, ${ }^{14}$ and deficits in fine and gross motor function are common. ${ }^{15}$ Evidence from neuroimaging of acquired cerebellar lesions suggests that disruption of reciprocal connections to the cortex during critical periods of development may contribute to impaired higher cognitive functions associated with autism symptomatology. ${ }^{16,17}$ Several cerebellar abnormalities have been observed in mouse models that either overexpress or underexpress $E N-2$. Ectopic overexpression of $E N-2$ during fetal development results in selective Purkinje cell loss, reduced cerebellar volume and delayed maturation and migration of the germinal layer. ${ }^{2,18}$ Further, EN-2 overexpression in late fetal and early-postnatal development in mice is associated with deficits in dentritogenesis and changes in the pattern of afferent innervation. ${ }^{4,19,20}$ However, for comparative purposes, it must be noted that rodent perinatal neurodevelopment (birth to postnatal days 2-7) approximately corresponds to the human third trimester. ${ }^{21}$ Interestingly, $E n-2^{-1-}$ knockout mice exhibit similar abnormal cerebellar patterning, reduced Purkinje cell numbers and abnormal dendritic foliation underscoring the importance of normal EN-2 regulation during neurodevelopment. ${ }^{22}$ In addition, the $E N-2$ null mice display abnormal behaviors relevant to autism

\footnotetext{
${ }^{1}$ Department of Pediatrics, University of Arkansas for Medical Sciences, Arkansas Children's Hospital Research Institute, Little Rock, AR, USA and ${ }^{2}$ Division of Biochemical Toxicology, National Center for Toxicological Research, Jefferson, AR, USA

Correspondence: Dr SJ James, Department of Pediatrics, University of Arkansas for Medical Sciences, Arkansas Children's Hospital Research Institute, 13 Children's Way Slot 512-41B, Little Rock, AR 72202, USA.
}

E-mail: jamesjill@uams.edu

Keywords: Autism; cerebellum; DNA; EN-2; Epigenetics; histone methylation

Received 4 November 2012; revised 18 Decemeber 2012; accepted 3 January 2013 
including deficits in social behaviors, spatial and memory tasks, and a cerebellar-specific increase in serotonin. ${ }^{23}$ Together, available evidence suggests that the failure to downregulate $E N-2$ expression late in development or decreased expression during embryogenesis results in altered cerebellar development that resembles postnatal cerebellar abnormalities in individuals with autism.

\section{Materials and methods}

Post-mortem Cerebellum. DNA and nuclei were isolated from frozen blocks of cerebellar cortex from 13 autism and 13 unaffected control individuals obtained from the National Institute of Child Health and Development Brain and Tissue Bank for Developmental Disorders at the University of Maryland, Baltimore, MD and from the Autism Tissue Program at the Harvard Brain Tissue Resource Center, Belmont, MA. All donors had a confirmed diagnosis of autism based on Diagnostic and Statistical Manual of Mental Disorders and Autistic Diagnostic Interview Revised. Autism and control groups were matched, as closely as possible for post-mortem interval (PMI), age, gender, race and cause of death.

Global DNA methylation. DNA was extracted from frozen cerebellum blocks using the Puregene DNA Purification kit (Qiagen, Valencia, CA, USA). Purified DNA was digested into component nucleotides as previously described in detail. ${ }^{24}$ DNA base separation and quantification of 5-methylcytosine (5-mC) and cytosine was performed with a Dionex HPLC-UV system (Sunnyvale, CA, USA) coupled to an electrospray ionization tandem mass spectrometer (Thermo-Finnigan LCQ, Waltham, MA, USA) using a Phenomenex Gemini column (C18, $150 \times 2.0 \mathrm{~mm}, 3 \mu \mathrm{m}$, Torrance, CA, USA) and expressed as percent 5-mC/total cytosine in DNA.

EN-2 promoter methylation by McrBC-PCR assay. DNA was extracted and purified with QIAamp DNA Micro Kit (Qiagen) according to the manufacturer's instructions. DNA concentration was determined by NanoDrop 2000c/2000 UV-Vis spectrophotomer (Thermo Fisher Scientific, Middletown, VA, USA) and quality was confirmed by agarose electrophoresis. Genomic DNA (400 ng) was digested with $10 \mathrm{U}$ of McrBC endonuclease (New England BioLabs, St Louis, MO, USA) overnight at $37^{\circ} \mathrm{C}$. McrBC is a methylation-specific endonuclease, which, as opposed to methylation-sensitive restriction (MSR) enzymes, cleaves DNA containing 5-mC on one or both strands, but does not act on unmethylated DNA. ${ }^{25}$ Strand breaks induced by cleavage of methylated DNA by McrBC abrogates PCR amplification, whereas unmethylated cytosines remain intact and can be detected by quantitative PCR product recovery. Following the McrBC treatment, quantitative PCR with primers within the $E N-2$ promoter (Figure 1) was used to analyze methylation status of $E N-2$ promoter. Undigested DNA served as control. Methylated genomic DNA from human male Jurkat cells (New England BioLabs) was used as DNA standard and given value of $100 \%$ methylation. Percent CpG methylation in the $E N-2$
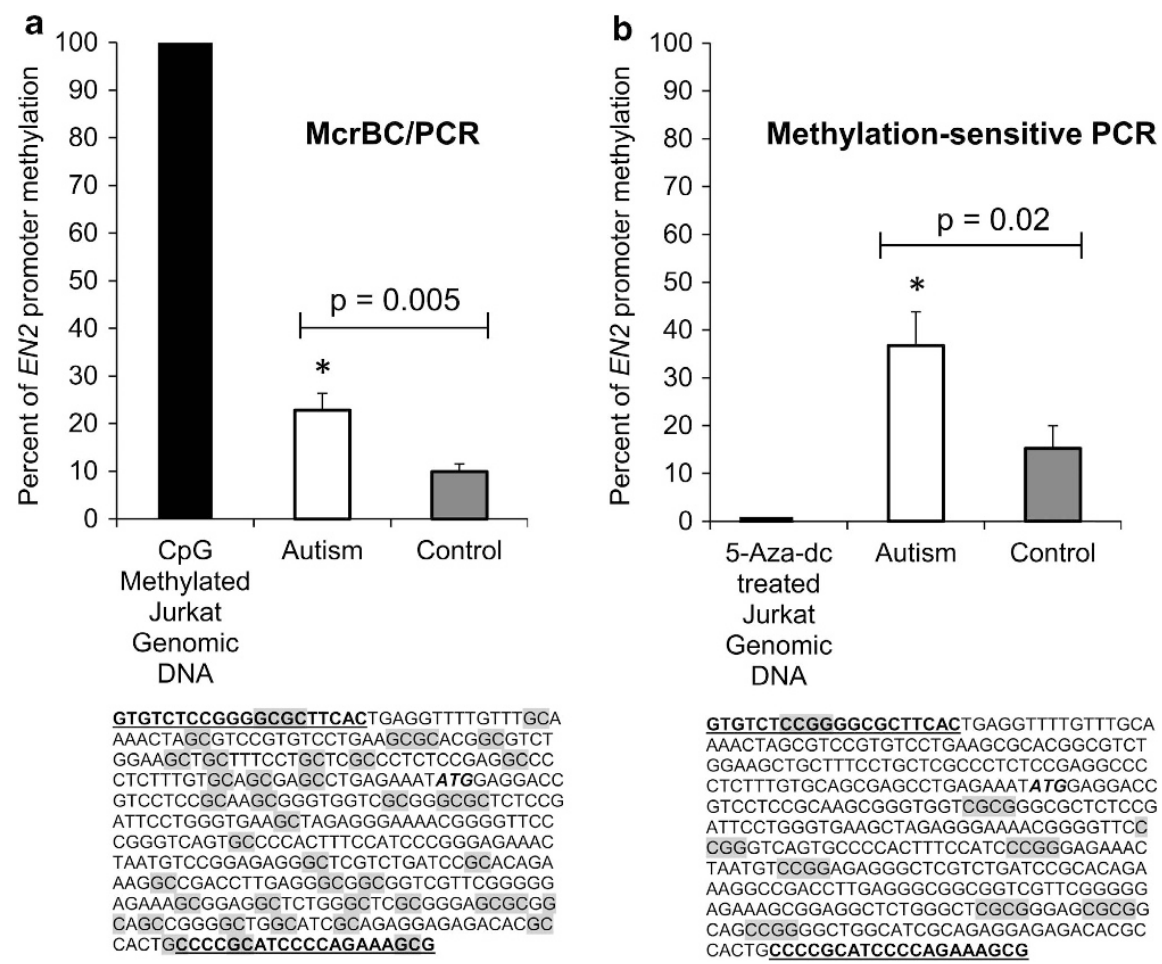

GTGTCTCCGGGGCGCTTCACTGAGGTTTTGTTTGCA AAACTAGCGTCCGTGTCCTGAAGCGCACGGCGTCT GGAAGCTGCTTTCCTGCTCGCCCTCTCCGAGGCCC CTCTTTGTGCAGCGAGCCTGAGAAATATGGAGGACC GTCCTCCGCAAGCGGGTGGTCGCGGGCGCTCTCCG ATTCCTGGGTGAAGCTAGAGGGAAAACGGGGTTCC CGGGTCAGTGCCCCACTTTCCATCCCGGGAGAAAC TAATGTCCGGAGAGGGCTCGTCTGATCCGCACAGA AAGGCCGACCT GAGGGGGGGT AGAAAGCGGAGGCTCTGGGCTCGCGGGAGCGCGG CACTGCCCCGCATCCCCAGAAAGCG

Figure 1 (a) Engrailed-2 (EN-2) promoter methylation status in 13 case and 13 control cerebellum samples using the McrBC-PCR restriction assay; target CpG sites for restriction within the $5^{\prime}$-promoter sequence are highlighted. (b) EN-2 promoter methylation status using methylation-sensitive restriction PCR with Hpall/BstUI restriction enzymes; target CpG sites within the $5^{\prime}$-promoter sequence are highlighted. 
promoter was calculated as ratio of PCR product recovery after DNA digestion with McrBC relative to undigested DNA, normalized to methylated Jurkat genomic DNA:

$$
\begin{gathered}
\left(\Delta \mathrm{Ct}^{\text {sample }} / \Delta \mathrm{Ct} \mathrm{t}^{\mathrm{CpG} \text { methylated jurkat genomic DNA }} \times 100 \%\right) \\
\text { where } \Delta \mathrm{Ct}=\mathrm{Ct} \mathrm{t}^{\text {digested DNA }}-\mathrm{Ct}^{\text {undigested DNA }} .
\end{gathered}
$$

EN-2 promoter methylation by MSR-PCR. Genomic DNA $(400 \mathrm{ng})$ was digested overnight with $5 \mathrm{U}$ of MSR endonuclease Hpall at $37^{\circ} \mathrm{C}$ following with $5 \mathrm{U}$ of MSR endonuclease BstUl at $60^{\circ} \mathrm{C}$ according to the manufacturer's instructions (New England BioLabs). Double digestion of DNA by Hpall/BstUI induces DNA strand breaks at unmethylated CCGG and CGCG sequences, and abrogates PCR amplification. $^{26}$ Conversely, methylated cytosines prevent enzyme cleavage and can be detected by PCR product recovery. Undigested DNA served as control. Unmethylated genomic DNA from human male Jurkat cells was used as a standard for EN-2 gene promoter methylation and given value of $0 \%$. The results are presented as ratio of PCR product recovery after the digestion of DNA with Hpall/BstUI relative to undigested DNA, normalized to 5-Aza-dc-treated Jurkat Genomic DNA:

$$
\begin{aligned}
& \% \text { methylation }=100 \%-\Delta \mathrm{Ct}^{\text {sample }} / \\
& \Delta \mathrm{Ct}^{5-\mathrm{Aza}-\mathrm{dc} \text { treated Jurkat Genomic DNA }} \times 100 \% ; \\
& \Delta \mathrm{Ct}=\mathrm{Ct} \text { digested DNA-Ct undigested DNA }
\end{aligned}
$$

EN-2 gene expression by quantitative reverse transcription PCR. Total RNA was extracted from cerebellum brain tissues using TRI Reagent (Ambion, Life Technologies, Grand Island, NY, USA) and purified with RNeasy Mini Kit (Qiagen). RNA quality (RNA integrity number) was assessed with Agilent RNA 6000 Nano Kit and Agilent 2100 Bioanalyzer (Agilent Technologies, Santa Clara, CA, USA). Total RNA $(2 \mu \mathrm{g})$ was reverse transcribed using random primers and a High Capacity complementary DNA Reverse Transcription Kit (Applied Biosystems, Foster City, CA, USA). The levels of EN-2 gene transcripts were determined in triplicate by quantitative reverse transcription PCR using TaqMan Gene Expression Assays (Hs00171321_m1*, Applied Biosystems). Relative quantification of gene expression was performed by using the glyceraldehyde-3-phosphate dehydrogenase (GAPDH) gene as an internal control. The EN-2 gene expression was presented as mean $2^{-\left(C_{\mathrm{T} E N-2}-C_{\mathrm{T}}{ }_{G A P D H}\right)}$ as described previously. ${ }^{27}$

Western blot analysis of EN-2 protein level. Brain tissue lysates were prepared by homogenization of $30 \mathrm{mg}$ of tissue in lysis buffer supplemented with protease and phosphatase inhibitors. Extracts $(50 \mu \mathrm{g})$ containing equal quantities of proteins were separated by SDS-polyacrylamide gel electrophoresis on $15 \%$ polyacrylamide gels and transferred to polyvinylidene difluoride membranes. Human fetal normal cerebellum (ab30070, Abcam) was used as positive control. Membranes were probed with primary antibodies against EN-2 protein (Rabbit polyclonal antibody to EN-2, ab28731, 1:1000, Abcam). Horseradish peroxidase-coupled donkey anti-rabbit secondary antibodies (Santa Cruz Biotechnology,
Santa Cruz, CA, USA) were used for visualization. Chemiluminescence detection was performed with the Immobilon Western Chemiluminescent horseradish peroxidase Substrate (Millipore Corporation, Billerica, MA, USA) and measured directly by a UVP BioSpectrum Imaging System (Upland, CA, USA). Equal protein loading was confirmed by immunostaining against $\beta$-actin (1:5000; Sigma-Aldrich, St Louis, MO, USA).

\section{Chromatin immunoprecipitation assay of $\mathrm{H} 3 \mathrm{~K} 4 \mathrm{me} 3$ and} H3K27me3. Chromatin immunoprecipitation (ChIP) assays were performed using the ChIP Assay Kit (Millipore) and primary antibodies: ChIPAb + Trimethyl-Histone H3 (Lys27) set and ChIPAb + Trimethyl-Histone H3 (Lys4) set. Positive and negative control antibodies were included according to the manufacturer's instructions. Purified immunoprecipitated DNA and input DNA were subsequently coamplified by quantitative PCR. The ChIP primers within the $E N-2$ promoter were designed with Primer-BLAST (http:// www.ncbi.nlm.nih.gov/tools/primer-blast/) tools based on the EN-2 promoter sequences shown in Figure 1. ChIP Primer Pair 1 covered the EN-2 ATG start site and included forward primer: 5'-TCCTGCTCGCCCTCTCCGAG-3' and reverse primer: 5'-ACTGACCCGGGAACCCCGTT-3' (product length-139bp). All assays were run in triplicate and data expressed as the mean ( \pm s.e.) percent input DNA after adjusting for total input DNA: $100 \times 2^{\text {(adjusted input } \mathrm{Ct}-\mathrm{IP} \mathrm{Ct})}$. Histone integrity was confirmed by western blot and gel electrophoresis.

Statistical analysis. Statistical analysis was performed using Graphpad Prism software (La Jolla, CA, USA). Normal distribution of the data was determined using the Kolmogorov-Smirnov test. The paired $t$-test was used for matched case-control data that were normally distributed and the nonparametric Wilcoxin matched-pairs signed-rank test was used for data that were not normally distributed. Correlations were determined using linear regression analysis within Graphpad software. Results are expressed as means \pm s.e.m. with statistical significance set at 0.05 .

\section{Results}

Demographics of tissue donors. The case-control tissue demographics are presented in Table 1. There were no mean differences in age, gender, race or PMI between the autism and control groups $(P>0.05)$. In both groups, 69\% $(9 / 13)$ of individuals were male. The mean age was 15.5 year \pm 9.5 in the autism group (eight children under 18 years and five adults) and 15.8 year \pm 8.6 (nine children under 18 years and four adults) in the control group. The mean PMI was $18.4 \pm 5.7 \mathrm{~h}$ for the autism samples and $15.7 \pm 6.2 \mathrm{~h}$ in the control samples. Age, gender, race and $\mathrm{PMI}$ were the primary variables matched between groups; however casecontrol matching for cause of death is more difficult given limited sample availability but these were matched as closely as possible. For example, asphyxia, smoke inhalation or aspiration in cases were matched to asthma and drowning in controls. Head trauma was matched with brain bruising and GI bleeding matched with multiple injuries. 
Table 1 Case-control tissue distribution

\begin{tabular}{|c|c|c|c|c|c|}
\hline Case no. & Gender $^{\mathrm{a}}$ & $A g e^{\mathrm{b}}$ & $P M I(\mathrm{~h})^{\mathrm{c}}$ & Race & Cause of death \\
\hline \multicolumn{6}{|l|}{ Autism cases } \\
\hline UMB 1182 & $\mathrm{~F}$ & 9 & 24 & $\begin{array}{l}\text { African } \\
\text { American }\end{array}$ & $\begin{array}{l}\text { Smoke } \\
\text { inhalation }\end{array}$ \\
\hline AN16115 & $\mathrm{F}$ & 11 & 13 & White & Drowning \\
\hline AN00764 & $M$ & 20 & 24 & White & Bruising of brain \\
\hline AN08792 & $\mathrm{M}$ & 30 & 20 & White & Gl Bleeding \\
\hline AN11989 & $M$ & 30 & 16 & White & Heart failure \\
\hline UMB 4671 & $\mathrm{~F}$ & 4 & 13 & $\begin{array}{l}\text { African } \\
\text { American }\end{array}$ & Multiple injuries \\
\hline UMB 4721 & M & 8 & 16 & $\begin{array}{l}\text { African } \\
\text { American }\end{array}$ & Drowning \\
\hline UMB 4231 & M & 8 & 12 & $\begin{array}{l}\text { African } \\
\text { American }\end{array}$ & Drowning \\
\hline AN19511 & $M$ & 8 & 22 & White & Sarcoma \\
\hline AN16641 & $\mathrm{M}$ & 9 & 27 & White & Seizure disorder \\
\hline UMB 4899 & $M$ & 14 & 9 & White & Drowning \\
\hline AN09730 & M & 22 & 25 & White & Aspiration \\
\hline AN12457 & $\mathrm{F}$ & 29 & 18 & White & Seizure disorder \\
\hline \multicolumn{6}{|l|}{ Control cases } \\
\hline UMB 1407 & $\mathrm{~F}$ & 9 & 20 & $\begin{array}{l}\text { African } \\
\text { American }\end{array}$ & Asthma \\
\hline UMB 0856 & $\mathrm{~F}$ & 29 & 7 & White & Asthma \\
\hline UMB 1322 & $M$ & 16 & 25 & White & Head trauma \\
\hline AN10833 & $M$ & 22 & 21 & Unknown & Unknown \\
\hline AN15622 & M & 30 & 15 & White & Asphyxia \\
\hline UMB 1708 & $\mathrm{~F}$ & 8 & 20 & $\begin{array}{l}\text { African } \\
\text { American }\end{array}$ & Multiple injuries \\
\hline UMB 1793 & M & 11 & 19 & $\begin{array}{l}\text { African } \\
\text { American }\end{array}$ & Drowning \\
\hline UMB 4787 & $\mathrm{M}$ & 12 & 15 & $\begin{array}{l}\text { African } \\
\text { American }\end{array}$ & Asthma \\
\hline UMB 4543 & $M$ & 28 & 13 & White & Multiple injuries \\
\hline UMB 616 & M & 12 & 25 & White & Multiple injuries \\
\hline UMB 1670 & $M$ & 13 & 5 & White & Asphyxia \\
\hline UMB 1185 & $\mathrm{M}$ & 4 & 17 & White & Drowning \\
\hline UMB 754 & $\mathrm{~F}$ & 11 & 12 & Unknown & Asthma \\
\hline
\end{tabular}

Abbreviations: F, female; M, male; PMI, post-mortem interval.

${ }^{a} N$ (\% male) for autism group: $11(69.3 \%) ; N$ (\% male) for control group: 11 (69.3\%). ${ }^{b}$ Mean (s.d.) age for autism group: 15.5 year (9.5); mean (s.d.) age for control group: 15.8 (8.6). ' Mean (s.d.) PMl for autism group: 18.4 (5.7); mean (s.d.) PMl for control group: 15.7 (6.2).

EN-2 promoter region methylation. The EN-2 promoter region was found to be significantly hypemethylated in the 13 cerebellar samples compared with 13 control samples as determined by the two independent methylation assays with different $\mathrm{CpG}$ recognition sites in the $E N-2$ promoter. Figure 1a presents the percent methylation in case and control samples across the EN-2 promoter as determined by McrBC-PCR assay. The percent methylated cytosines in the autism cerebellum was $23 \pm 4 \%$ compared with $10 \pm 2 \%$ in the control samples $(P=0.005)$. The second assay, MSRPCR confirmed the McrBC results and demonstrated similar EN-2 promoter region hypemethylation (Figure 1b) with $38 \pm 7 \%$ of the CCGG and CGCG sites methylated compared with $15 \pm 5 \%$ in controls $(P=0.02)$. The results from both methylation assays were highly correlated $(P=0.037$; data not shown). Together, these results confirm that the EN-2 promoter region in the autism cerebellar cortex is significantly hypemethylated relative to that of unaffected controls.

Global DNA methylation. Global DNA methylation was quantified in using tandem mass spectrometry and expressed as the percent $5-\mathrm{mC} /$ total cytosine content in
DNA. In contrast to global DNA hypomethylation previously reported in immune cells from children with autism, ${ }^{28}$ DNA extracted from autism cerebellum samples was significantly hypermethylated relative to control samples. The mean percent $5-\mathrm{mC} \pm$ s.d. was $5.9 \pm 1.2$ in 13 case cerebellum compared with $4.7 \pm 1.1$ in 13 controls $(P=0.002)$ and is presented in Figure 2a. The positive correlation between $E N-2$ promoter methylation and global DNA methylation ( $\% 5-\mathrm{mC})$ is shown in Figure $2 \mathrm{~b}$ $(P=0.016)$.

EN-2 gene expression. To assure RNA integrity and valid gene expression data from post-mortem samples, RNA integrity number was determined using the Agilent RNA 6000 Nano Kit and Agilent 2100 Bioanalyzer (Agilent Technologies). The mean RNA integrity number value for cerebellar and control samples was $6.7 \pm 1.5$ (range 5.98.3), which is considered to be excellent quality for the quantitative reverse transcription PCR gene expression analysis. GADPH was used as reference control and has been previously validated as a stable reference gene in postmortem cerebellar tissues and found not to be correlated with age, PMI or cause of death. ${ }^{29}$ Unexpectedly, the mean gene expression level of EN-2 was significantly higher in the autism samples despite evidence of promoter region hypermethylation. As shown in Figure $3 a$, the mean \pm s.e. amount of target RNA in the autism cerebellum was $0.09 \pm 0.02$ and $0.04 \div 0.003$ in control samples $(P=0.04)$. In Figure $3 \mathrm{~b}$, the positive correlation between EN-2 promoter methylation in case and control samples, and EN-2 gene expression is shown $(P=0.007)$.

EN-2 protein level. Given the unexpected increase in EN-2 gene expression in the presence of promoter region hypermethylation, levels of EN-2 protein were then evaluated by western blot and expressed as fluorescence units (DLU) normalized to $\beta$-actin. As shown in Figure 3c, EN-2 protein levels in the cerebellum were significantly increased in the autism cerebellar samples $(9.2 \pm 0.86 \mathrm{DLU})$ compared with the control samples $(6.8 \pm 0.55 \mathrm{DLU})$ with a $P$-value of 0.02 . The increased level of EN-2 protein is consistent with the increase in EN-2 gene expression (Figure 3a).

EN-2 promoter region trimethylation of histones H3K27 and H3K4. The methylation status of histones H3K27 (associated with gene silencing) and histone $\mathrm{H} 3$ lysine 4 (H3K4; associated with gene activation) was investigated as a possible explanation for the increased EN-2 gene expression in the presence of promoter region DNA hypermethylation. The content and integrity of histone protein was confirmed by western blot and gel electrophoresis. Two samples from both case and control groups were omitted from the ChIP analysis due to histone degradation resulting in 11 case and 11 control samples. There was no difference in histone content between the remaining analyzed samples in case and control samples (115767 \pm 12786 and $124,578 \pm 11541$ fluorescent units, respectively; $P=0.6$ ). Figure 4 presents ChIP results as the calculated percent input of immunoprecipitated DNA for histone H3K4 trimethylation and histone H3K27 trimethylation after normalization to 

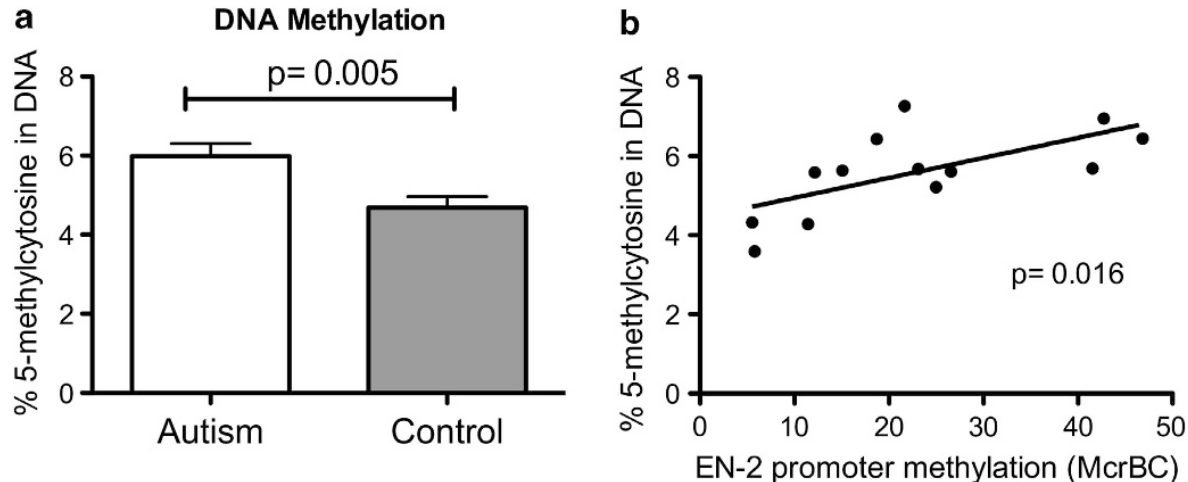

Figure 2 (a) Global DNA methylation (percent 5-methylcytosine (5-mC)/total cytosine) in 13 case and 13 control cerebellar samples. (b) Positive correlation between percent 5-mC in DNA and engrailed-2 (EN-2) promoter methylation.

a

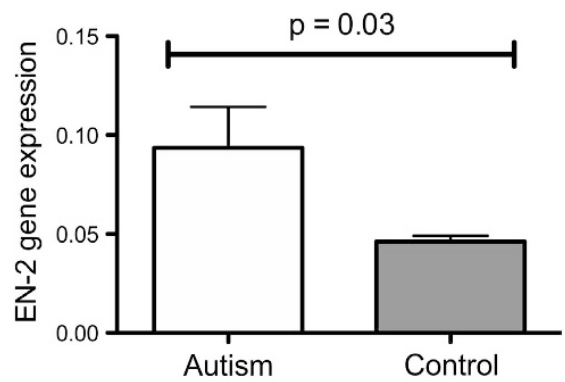

b

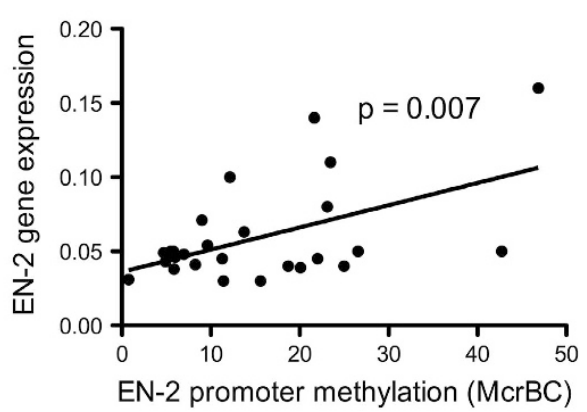

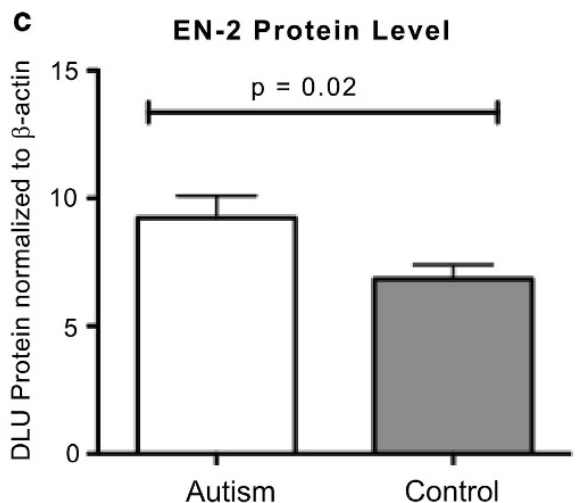

Figure 3 (a) Engrailed-2 (EN-2) gene expression in 13 case and 13 control tissue samples. The expression of $E N-2$ gene was determined by quantitative reverse transcription PCR and presented as mean $2^{-\left(C_{T} E_{N-2}-C_{T}{ }_{G A P O H}\right)}$ as described previously. ${ }^{27}$ (b) Positive correlation between EN-2 promoter methylation and $E N-2$ gene expression. (c) Level of EN-2 protein in 13 case and 13 control cerebellar samples.

total input DNA. The mean level of H3K27 trimethylation (associated with gene repression) was significantly decreased in the autism compared with control samples $(P=0.02)$, and the mean level of histone H3K4 trimethylation (associated with gene activation) in the EN-2 promoter was increased in autism relative to the matched control samples with marginal significance $(P=0.11)$.

\section{Discussion}

The elucidation of epigenetic alterations in the autism brain has the potential to provide new insights into the molecular mechanisms underlying abnormal gene expression associated with this disorder. The epigenetic evaluation of $E N-2$ in the autism cerebellum herein indicates a persistent upregulation of this developmentally expressed homobox gene that normally undergoes perinatal downregulation to insure normal timing and onset of Purkinje cell differentiation. The results of the present investigation are consistent with the possibility that the sustained EN-2 overexpression may be due to epigenetic abnormalities in histone methylation patterns that may contribute to Purkinje cell loss in some individuals with autism.

Recent studies in humans and rodent models have discovered an unexpected connection between gene promoter DNA/histone methylation and memory formation, learning 

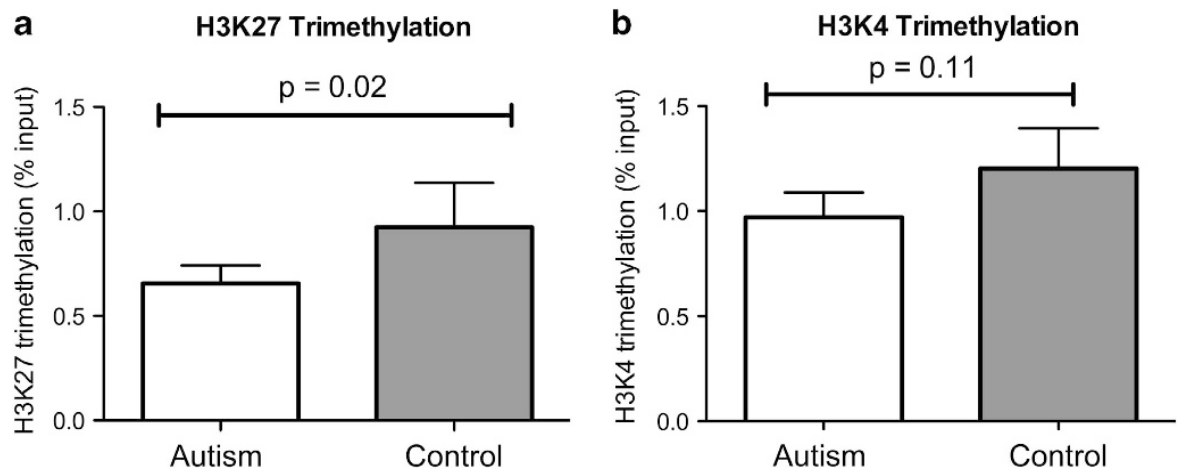

Figure 4 (a) Histone H3 lysine 27 (H3K27) trimethylation within the engrailed-2 (EN-2) promoter region in 11 case and 11 control cerebellar samples. (b) Histone H3 lysine 4 (H3K4) trimethylation within the $E N-2$ promoter region in 11 case and 11 control cerebellar samples.

and behavior. For example, epigenetic alterations in brain-derived neurotrophic factor gene expression in the hippocampus were associated with changes in brain-derived neurotrophic factor promoter methylation and memory consolidation after contextual fear conditioning or after early-life maltreatment in mouse models. ${ }^{30,31}$ In addition to DNA methylation changes, histone modification and chromatin remodeling have been similarly implicated in synaptic plasticity and learning behavior. ${ }^{32-34}$ These results suggest that DNA methylation and histone modifications are dynamically regulated in brain and may contribute to deficits in attention, learning, heritable memory and altered behavioral phenotype in autism. ${ }^{35}$ Evidence of the cerebellar contribution to autism core symptoms and behaviors has been detailed recently in two excellent reviews. ${ }^{16,17}$ Deficits in attention, cognitive function, affective behavior, visual-spatial organization and expressive language have been documented in multiple neuroimaging studies and reports of localized cerebellar lesions. ${ }^{36,37}$ Fine and gross motor impairments are common among individuals with autism and have been associated with symptom severity. ${ }^{15}$ Interestingly, enhanced motor skills in 2-year-old children with autism was a predictor of the subsequent loss of diagnosis at 4 years of age and implicates cerebellar involvement in autism symptom severity and prognosis. ${ }^{38}$

The increase in EN-2 gene expression and protein levels in the presence of global and promoter region DNA hypermethylation was an unexpected finding for two reasons. In a previous report, we documented genome-wide DNA hypomethylation in immune cells from children with autism relative to age-matched controls. The discordant results in brain and immune cells suggest that alterations in DNA methylation density occur in a tissue-specific manner in autism and that peripheral cell DNA methylation patterns may not be a valid surrogate for alterations in the brain. Secondly, we had expected that $E N-2$ promoter region hypermethylation would be associated with a decrease in gene expression as previously reported for the MeCP2 promoter in autism cerebral cortex ${ }^{39}$ and for many cancer-related tumor suppressor genes ${ }^{40}$ and in schizophrenia. ${ }^{41}$ However, recent reports of gene activation despite the presence of promoter hypermethylation have emerged to underscore the complexity and multiple layers of molecular control involved in the regulation of gene expression. ${ }^{42}$ It is possible that promoter DNA hypermethylation of the EN-2 gene in the autism cerebellum preceded the histone modifications, and was initially intended to support downregulation of $E N-2$ during perinatal development. However, the observed increase in $E N-2$ gene and protein expression would argue that transcriptional upregulation by other epigenetic mechanisms predominated over the repressive tendencies of DNA cytosine methylation. This suggestion is supported by previous reports showing either a high expression of genes, for example, hTERT, despite their promoter DNA hypermethylation, or reactivation of silenced genes, for example, SFRP1, Ecadherin, without loss of promoter DNA hypermethylation. ${ }^{43-45}$

The increase in EN-2 gene and protein level in the autism cerebellum may be partly explained by alterations in promoter histone $\mathrm{H} 3$ methylation status. The significant decrease in H3K27 trimethylation (gene repression) was accompanied by a marginally significant increase in H3K4 trimethylation (gene activation) (Figure 4). Both of these alterations, independently or combined, have been associated with gene upregulation during early development. Consistent with our results, several recent studies have attributed expression/reactivation of DNA hypermethylated genes to the increased levels of upregulating histone marks, for example, acetyl-H3K9, methyl-H3K4 or reduced levels of repressive chromatin marks, for example, trimethyl-H3K9 and trimethyl-H3K27. ${ }^{41-43}$

The patterns of histone H3K27 and H3K4 trimethylation are dynamically regulated during early development by specific methyltransferases and demethylases, and are thought to underlie the establishment of lineage-specific gene expression programs in the brain. For example, a recently identified H3K27 trimethylation-specific demethylase, JMJD3, has been shown to mediate the upregulation of key genes involved in neurogenesis and the commitment to the neural lineage, including homeobox genes such as EN-2. ${ }^{46,47}$ Interestingly, JMJD3 demethylase expression was found to be acutely upregulated in endothelial cells under conditions of oxidative stress following spinal cord injury. The associated decrease in H3K27 trimethylation in the IL-6 gene promoter suggests a regulatory role for this histone modification in the induction of the neuroinflammatory response. Consistent with these observations, our group recently reported evidence of 
oxidative stress associated with protein and DNA damage in the identical cerebellar samples evaluated in this report. ${ }^{48}$ Finally, the tissue-specific distribution of MeCP2 in the brain has been shown to be due to its association with chromatin regions containing trimethylated $\mathrm{H} 3 \mathrm{~K} 27$. The significant decrease in H3K27 trimethylation observed in the present study could offer an alternative mechanism for the inability of MeCP2 to bind to DNA. Mutations in MeCP2 have been associated with comorbid autism in Rett syndrome and similarly prevent MeCP2 DNA binding resulting in gene overexpression. In future studies, it will be important to determine whether the binding of MeCP2 to the EN-2 promoter is decreased and correlated with $E N-2$ overexpression as a converging genetic/epigenetic mechanism.

Similar to H3K27, reversible methylation and demethylation of H3K4 dynamically alters gene expression during early stages of development in mouse models. ${ }^{49}$ In humans, a patient with autism was recently found to have a missense mutation in the JARID1C gene that codes for the H3K4 demethylase, which functions as a transcriptional repressor by removing methyl groups from trimethylated H3K4. Inactivation of this specific H3K4 demethylase gene by mutation would be consistent with sustained H3K4 trimethylation and overexpression of affected genes, including EN-2. These recent discoveries have launched the concept that histone $\mathrm{H} 3$ methylation/demethylation is a dynamic process that can reversibly mediate gene expression and repression in a cellspecific manner during programmed stages of cell differentiation and neuronal lineage commitment. Thus, the observed overexpression of $E N-2$ in the autism cerebellum may reflect a failure to downregulate $E N-2$ expression appropriately during perinatal cerebellar cell development. ${ }^{2}$

Based on the findings reported here, EN-2 may now be included in the several candidate genes that have both genetic and epigenetic associations with autism including brain-derived neurotrophic factor, ${ }^{50,51} R E L N,{ }^{52,53}$ oxytocin, ${ }^{54,55}$ HOXA1, ${ }^{56,57} \mathrm{MeCP} 2,{ }^{58}$ and $\mathrm{FXS}^{59}$ In addition, five independent family-based studies have identified polymorphic variation in $E N-2$ as an autism susceptibility gene., ${ }^{1,60-63}$ Whereas functional alterations due to DNA mutations would be expected to be irreversible, epigenetic factors have potential for modulation and reversibility with targeted interventions. In a major advance, a subject-specific approach was recently published on genome-wide mapping of $\mathrm{H} 3 \mathrm{~K} 4$ trimethylation in prefrontal cortex of 16 subjects with an autism spectrum disorder. ${ }^{62}$ A complex pattern emerged with hundreds of loci showing unique subject-specific alterations in $\mathrm{H} 3 \mathrm{~K} 4$ methylation in genes regulating neuronal connections and social behaviors, often in conjunction with altered gene expression. Several recent reports of altered histone methylation at gene promoters during brain development and the essential regulatory role of histone-specific methylases and demethylases have provided new insights into potential mechanisms underlying altered gene expression in complex neurodevelopmental disease. ${ }^{49,64,65}$

In summary, this is the first case-control study to evaluate the expression and epigenetics of the developmentally regulated homeobox gene $E N-2$ in the autism brain. The results suggest that the unexpected gene and protein overexpression in the presence of promoter DNA methylation may be partially explained by over-riding histone methylation patterns in H3K27 and H3K4. The observation of genomewide and promoter-specific DNA hypermethylation in the autism cerebellum is contrary to that previously reported in peripheral lymphocytes from children with autism, and suggests that peripheral cells may not always reflect epigenetic alterations in the brain and brain-specific gene expression in autism. Research into the contribution of epigenetic abnormalities to autism pathogenesis and pathophysiology is an emerging and challenging new field that compliments and extends the search for autism susceptibility genes.

\section{Conflict of interest}

The authors declare no conflict of interest.

Acknowledgements. We would like to thank the families of individuals with autism for the thoughtful donation of post-mortem tissues to the Autism Tissue Program at the Harvard Brain Tissue Resource Center and the NICHD Brain and Tissue Bank for Developmental Disorders at the University of Maryland. This study was sponsored by National Institute of Child Health and Development; grant number: 1RO1HD051873, Arkansas Biosciences Institute and Jane Botsford Johnson Foundation.

1. Benayed R, Choi J, Matteson PG, Gharani N, Kamdar S, Brzustowicz LM et al. Autismassociated haplotype affects the regulation of the homeobox gene, ENGRAILED 2. Biol Psychiatry 2009; 66: 911-917.

2. Jankowski J, Holst MI, Liebig C, Oberdick J, Baader SL. Engrailed-2 negatively regulates the onset of perinatal Purkinje cell differentiation. J Comp Neurol 2004; 472: 87-99.

3. Mehler MF, Purpura DP. Autism, fever, epigenetics and the locus coeruleus. Brain Res Rev 2009; 59: 388-392.

4. Holst MI, Maercker C, Pintea B, Masseroli M, Liebig C, Jankowski J et al. Engrailed-2 regulates genes related to vesicle formation and transport in cerebellar Purkinje cells. $\mathrm{Mol}$ Cell Neurosci 2008; 38: 495-504.

5. Zec N, Rowitch DH, Bitgood MJ, Kinney HC. Expression of the homeobox-containing genes EN1 and EN2 in human fetal midgestational medulla and cerebellum. J Neuropathol Exp Neurol 1997; 56: 236-242.

6. Logan C, Hanks MC, Noble-Topham S, Nallainathan D, Provart NJ, Joyner AL. Cloning and sequence comparison of the mouse, human, and chicken engrailed genes reveal potential functional domains and regulatory regions. Dev Genet 1992; 13: 345-358.

7. Liu J, Nyholt DR, Magnussen P, Parano E, Pavone P, Geschwind D et al. A genomewide screen for autism susceptibility loci. Am J Hum Genet 2001; 69: 327-340.

8. Alarcon M, Cantor RM, Liu J, Gilliam TC, Geschwind DH. Evidence for a language quantitative trait locus on chromosome $7 q$ in multiplex autism families. Am. J Hum Genet 2002; 70: 60-71.

9. Whitney ER, Kemper TL, Bauman ML, Rosene DL, Blatt GJ. Cerebellar Purkinje cells are reduced in a subpopulation of autistic brains: a stereological experiment using calbindinD28k. Cerebellum 2008; 7: 406-416.

10. Bauman M, Kemper TL. Histoanatomic observations of the brain in early infantile autism. Neurology 1985; 35: 866-874.

11. Courchesne $E$. Brainstem, cerebellar and limbic neuroanatomical abnormalities in autism. Curr Opin Neurobiol 1997; 7: 269-278.

12. Amaral DG, Schumann CM, Nordahl CW. Neuroanatomy of autism. Trend Neurosci 2008; 31: 137-145.

13. Kamiya J, Aoki Y. Associations between hyperglycaemia and somatic transversion mutations in mitochondrial DNA of people with diabetes mellitus. Diabetologia 2003; 46: 1559-1566.

14. Courchesne E, Yeung-Courchesne R, Press GA, Hesselink JR, Jernigan TL. Hypoplasia of cerebellar vermal lobules VI and VII in autism. N Engl J Med 1988; 318: 1349-1354.

15. Freitag CM, Kleser C, Schneider M, von Gontard A. Quantitative assessment of neuromotor function in adolescents with high functioning autism and Asperger Syndrome. J Autism Develop Disord 2007; 37: 948-959.

16. Fatemi SH, Aldinger KA, Ashwood P, Bauman ML, Blaha CD, Blatt GJ et al. Consensus paper: pathological role of the cerebellum in autism. Cerebellum 2012; 11: 777-807.

17. O'Halloran CJ, Kinsella GJ, Storey E. The cerebellum and neuropsychological functioning: a critical review. J Clin Exp Neuropsychol 2012; 34: 35-56.

18. Baader SL, Sanlioglu S, Berrebi AS, Parker-Thornburg J, Oberdick J. Ectopic overexpression of engrailed-2 in cerebellar Purkinje cells causes restricted cell loss and 
retarded external germinal layer development at lobule junctions. J Neurosci 1998; 18: 1763-1773.

19. Cheng Y, Sudarov A, Szulc KU, Sgaier SK, Stephen D, Turnbull DH et al. The engrailed homeobox genes determine the different foliation patterns in the vermis and hemispheres of the mammalian cerebellum. Development 2010; 137: 519-529.

20. Sillitoe RV, Vogel MW, Joyner AL. Engrailed homeobox genes regulate establishment of the cerebellar afferent circuit map. J Neurosci 2010; 30: 10015-10024.

21. Clancy B, Finlay BL, Darlington RB, Anand KJ. Extrapolating brain development from experimental species to humans. Neurotoxicology 2007; 28: 931-937.

22. Kuemerle B, Zanjani H, Joyner A, Herrup K. Pattern deformities and cell loss in Engrailed-2 mutant mice suggest two separate patterning events during cerebellar development J Neurosci 1997; 17: 7881-7889.

23. Cheh MA, Millonig JH, Roselli LM, Ming X, Jacobsen E, Kamdar S et al. En2 knockout mice display neurobehavioral and neurochemical alterations relevant to autism spectrum disorder. Brain Res 2006; 1116: 166-176.

24. Friso S, Choi SW, Dolnikowski GG, Selhub J. A method to assess genomic DNA methylation using high-performance liquid chromatography/electrospray ionization mass spectrometry. Anal Chem 2002; 74: 4526-4531.

25. Sutherland E, Coe L, Raleigh EA. McrBC: a multisubunit GTP-dependent restriction endonuclease. J Mol Biol 1992; 225: 327-348.

26. Hashimoto K, Kokubun S, Itoi E, Roach HI. Improved quantification of DNA methylation using methylation-sensitive restriction enzymes and real-time PCR. Epigenetics 2007; 2: $86-91$.

27. Schmittgen TD, Livak KJ. Analyzing real-time PCR data by the comparative $C(T)$ method. Nat Protoc 2008; 3: 1101-1108.

28. Melnyk S, Fuchs GJ, Schulz E, Lopez M, Kahler SG, Fussell JJ et al. Metabolic imbalance associated with methylation dysregulation and oxidative damage in children with autism. J Autism Dev Disord 2012; 42: 367-377.

29. Koppelkamm A, Vennemann B, Fracasso T, Lutz-Bonengel S, Schmidt U, Heinrich M. Validation of adequate endogenous reference genes for the normalisation of qPCR gene expression data in human post mortem tissue. Int $J$ Legal Med 2010; 124: 371-380.

30. Lubin FD, Roth TL, Sweatt JD. Epigenetic regulation of BDNF gene transcription in the consolidation of fear memory. J Neurosci 2008; 28: 10576-10586.

31. Roth TL, Lubin FD, Funk AJ, Sweatt JD. Lasting epigenetic influence of early-life adversity on the BDNF gene. Biol Psychiatry 2009; 65: 760-769.

32. Levenson JM, O'Riordan KJ, Brown KD, Trinh MA, Molfese DL, Sweatt JD. Regulation of histone acetylation during memory formation in the hippocampus. J Biol Chem 2004; 279: 40545-40559.

33. Hsieh J, Gage FH. Chromatin remodeling in neural development and plasticity. Curr Opin Cell Biol 2005; 17: 664-671.

34. Fischer A, Sananbenesi F, Wang X, Dobbin M, Tsai LH. Recovery of learning and memory is associated with chromatin remodelling. Nature 2007; 447: 178-182.

35. Levenson JM, Sweatt JD. Epigenetic mechanisms in memory formation. Nat Rev Neurosci 2005; 6: 108-118.

36. Schmahmann JD, Caplan D. Cognition, emotion and the cerebellum. Brain 2006; 129(Pt 2): 290-292.

37. Schmahmann JD, Sherman JC. The cerebellar cognitive affective syndrome. Brain 1998; 121(Pt 4): 561-579.

38. Sutera S, Pandey J, Esser EL, Rosenthal MA, Wilson LB, Barton M et al. Predictors of optimal outcome in toddlers diagnosed with autism spectrum disorders. J Autism Dev Disord 2007; 37: 98-107.

39. Nagarajan RP, Hogart AR, Gwye Y, Martin MR, LaSalle JM. Reduced MeCP2 expression is frequent in autism frontal cortex and correlates with aberrant MECP2 promoter methylation. Epigenetics 2006; 1: 172-182.

40. Esteller M, Corn PG, Baylin SB, Herman JG. A gene hypermethylation profile of human cancer. Cancer Res 2001; 61: 3225-3229.

41. Grayson DR, Jia X, Chen Y, Sharma RP, Mitchell CP, Guidotti A et al. Reelin promoter hypermethylation in schizophrenia. Proc Natl Acad Sci USA 2005; 102: 9341-9346.

42. Raynal NJ, Si J, Taby RF, Gharibyan V, Ahmed S, Jelinek J et al. DNA methylation does not stably lock gene expression but instead serves as a molecular mark for gene silencing memory. Cancer Res 2012; 72: 1170-1181.

43. Zinn RL, Pruitt K, Eguchi S, Baylin SB, Herman JG. hTERT is expressed in cancer cell lines despite promoter DNA methylation by preservation of unmethylated DNA and active chromatin around the transcription start site. Cancer Res 2007; 67: 194-201.

44. Pruitt K, Zinn RL, Ohm JE, McGarvey KM, Kang SH, Watkins DN et al. Inhibition of SIRT1 reactivates silenced cancer genes without loss of promoter DNA hypermethylation. PLOS Genet 2006; 2: e40.
45. Tryndyak VP, Beland FA, Pogribny IP. E-cadherin transcriptional down-regulation by epigenetic and microRNA-200 family alterations is related to mesenchymal and drug-resistant phenotypes in human breast cancer cells. Int $J$ Cancer 2010; 126: 2575-2583.

46. Burgold T, Spreafico F, De Santa F, Totaro MG, Prosperini E, Natoli G et al. The histone H3 lysine 27-specific demethylase Jmjd3 is required for neural commitment. PloS one 2008; 3: e3034.

47. Agger K, Cloos PA, Christensen J, Pasini D, Rose S, Rappsilber J et al. UTX and JMJD3 are histone H3K27 demethylases involved in HOX gene regulation and development. Nature 2007; 449: 731-734.

48. Rose S, Melnyk S, Trusty TA, Pavliv O, Seidel L, Li J et al. Intracellular and extracellular redox status and free radical generation in primary immune cells from children with autism. Autism Res Treat 2012; 2012: 986519.

49. Wynder C, Stalker L, Doughty ML. Role of H3K4 demethylases in complex neurodevelopmental diseases. Epigenomics 2010; 2: 407-418.

50. Raznahan A, Toro R, Proitsi P, Powell J, Paus T, FB P et al. A functional polymorphism of the brain derived neurotrophic factor gene and cortical anatomy in autism spectrum disorder. J Neurodev Disord 2009; 1: 215-223.

51. Fuchikami M, Yamamoto S, Morinobu S, Takei S, Yamawaki S. Epigenetic regulation of BDNF gene in response to stress. Psychiatry Investig 2010; 7: 251-256.

52. Skaar DA, Shao Y, Haines JL, Stenger JE, Jaworski J, Martin ER et al. Analysis of the RELN gene as a genetic risk factor for autism. Mol Psychiatry 2005; 10: 563-571.

53. Lintas C, Persico AM. Neocortical RELN promoter methylation increases significantly after puberty. Neuroreport 2010; 21: 114-118.

54. Munesue T, Yokoyama S, Nakamura K, Anitha A, Yamada K, Hayashi K et al. Two genetic variants of CD38 in subjects with autism spectrum disorder and controls. Neurosci Res 2010; 67: 181-191.

55. Gregory SG, Connelly JJ, Towers AJ, Johnson J, Biscocho D, Markunas CA et al. Genomic and epigenetic evidence for oxytocin receptor deficiency in autism. BMC Med 2009; 7: 62.

56. Raznahan A, Lee $\mathrm{Y}$, Vaituzis C, Tran L, Mackie S, Tiemeier $\mathrm{H}$ et al. Allelic variation within the putative autism spectrum disorder risk gene homeobox $A 1$ and cerebellar maturation in typically developing children and adolescents. Autism Res 2012; 5: 93-100.

57. Stodgell CJ, Ingram JL, O'Bara M, Tisdale BK, Nau H, Rodier PM. Induction of the homeotic gene Hoxa1 through valproic acid's teratogenic mechanism of action. Neurotoxicol Teratol 2006; 28: 617-624.

58. Lopez-Rangel E, Lewis ME. Loud and clear evidence for gene silencing by epigenetic mechanisms in autism spectrum and related neurodevelopmental disorders. Clin Genet 2006; 69: 21-22.

59. Hagerman RJ, Ono MY, Hagerman PJ. Recent advances in fragile X: a model for autism and neurodegeneration. Curr Opin Psychiatry 2005; 18: 490-496.

60. Gharani N, Benayed R, Mancuso V, Brzustowicz LM, Millonig JH. Association of the homeobox transcription factor, ENGRAILED 2, 3, with autism spectrum disorder. Mol Psychiatry 2004; 9: 474-484.

61. Sen B, Singh AS, Sinha S, Chatterjee A, Ahmed S, Ghosh S et al. Family-based studies indicate association of Engrailed 2 gene with autism in an Indian population. Genes Brain Behav 2010; 9: 248-255.

62. Carayol J, Schellenberg GD, Tores F, Hager J, Ziegler A, Dawson G. Assessing the impact of a combined analysis of four common low-risk genetic variants on autism risk. Mol Autism 2010; $1: 4$.

63. Yang P, Shu BC, Hallmayer JF, Lung FW. Intronic single nucleotide polymorphisms of engrailed homeobox 2 modulate the disease vulnerability of autism in a han chinese population. Neuropsychobiology 2010; 62: 104-115.

64. Stadler F, Kolb G, Rubusch L, Baker SP, Jones EG, Akbarian S. Histone methylation at gene promoters is associated with developmental regulation and region-specific expression of ionotropic and metabotropic glutamate receptors in human brain. J Neurochem 2005; 94: 324-336.

65. Akbarian S, Huang HS. Epigenetic regulation in human brain-focus on histone lysine methylation. Biological Psychiatry 2009; 65: 198-203.

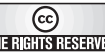

Translational Psychiatry is an open-access journal published by Nature Publishing Group. This work is licensed under the Creative Commons Attribution-NonCommercial-No Derivative Works 3.0 Unported License. To view a copy of this license, visit http://creativecommons.org/licenses/by-nc-nd/3.0/ 